\title{
A Case Report of Resin Facing Implant Restoration in Maxillary Anterior Incisor
}

\begin{abstract}
Keywords
Asymmetrical central incisor; Esthetic perception; Patient oriented restoration; Subjective perception

Abstract

Implant restorations may be challenging when attempting to satisfy patients even with the recent advances in materials and techniques. In this case report, the patient had fractured implant at the \#8 site that was removed and healed for 3 months. This resulted in a class II Siebert bone defect. The patient followed the treatment suggested by the dentist and achieved soft tissue esthetics but decided to choose the restoration according to his esthetic perceptions. This report shows that the esthetic is subjective based on a patients desire. Objective esthetic evaluation is supported by science and research. However, the final decision concerning esthetics is determined according to a patient's perception. For patient's satisfaction the clinician, most respect the patient's decision.
\end{abstract}

\section{Introduction}

Replacement of missing anterior teeth has always been a challenge for clinicians due to high patient esthetic demands [1]. From a patient's point of view, extraction and replacement of an anterior tooth can be a very psychological and emotional experience. In the past, the choice of treatment was based for the most part on the clinician's assessment of function and esthetics [2]. Although a clinician's evaluation criteria may be backed by science and experience, with the proliferation of dental treatment information based on social media, patients have become more critical and selective of their own esthetic choices [3]. Therefore, the patient must always be part of decision planning to determine a successful outcome of treatment [4]. Moreover the outcome of treatment is often centered on patient's satisfaction [5]. Consequently, the growing demand and awareness of esthetics have led to increased patient involvement in treatment planning of cases. Esthetic criteria are often influenced by a patient's sex, age, culture, expectation and psychological factors [3]. This report presents a case in which surgical and prosthetic decisions were, in large part, based on the patient's desires and input.

\section{Material and Methods}

The clinical data in this study was obtained from Implant Database (ID). This data was extracted as de-identified information from the routine treatment of patients at the Ashman Department of Period ontology and Implant Dentistry at the New York University College of Dentistry (NYUCD) Kriser Dental Center. The ID was certified by the Office of Quality Assurance at NYUCD. This study is in compliance with the Health Insurance Portability and Accountability Act (HIPAA) requirements and approved by the University Committee on Activities involving Human Subjects.

\section{Journal of Oral Biology}

Hengjeerajaras $P^{*}$, Kim KB, Mandali B, Hu G, Huang JT, Guallart IF, AI Khalil R and Ashman A

Department of Periodontology and Implant Dentistry, New York University College of Dentistry, USA

\section{*Address for Correspondence}

Hengjeerajaras P, Department of Periodontology and Implant Dentistry, New York University College of Dentistry, USA

Submission: 14 April, 2019

Accepted: 11 May, 2019

Published: 15 May, 2019

Copyright: (๑ 2019 Hengjeerajaras P, et al. This is an open access article distributed under the Creative Commons Attribution License, which permits unrestricted use, distribution, and reproduction in any medium, provided the original work is properly cited.

A 69 years old African American man was referred for \#8 fractured implant to New York University College of Dentistry Ashman Department of Period ontology and Implant Dentistry. Clinical and radiographic evaluations were performed (Figure 1a-c and 2). Under local anesthesia (2\% lidocaine, 1:100,000 epinephrine) the fractured implant was removed with a trephine bur (Figure 3). The patient rejected a flipper or a clear vacuum formed retainer due to financial issue on missing \#8siteat that moment. An analysis of esthetics of the upper incisors was performed. Three options were considered including 1) A new implant supported crown, 2) A fixed bridge \#7-\#9, 3) A removable denture. These three options were presented to the patient. The patient desired a new implant and fixed restoration. Following three months of healing, the horizontal ridge was intact with $2 \mathrm{~mm}$ vertical defect. A crestal incision was performed and a full thickness flap was elevated. Straumann implant osteotomy protocol was followed. A new implant (Straumann $4.1 \times 12 \mathrm{~mm}$ Roxolid SLActive) was placed without surgical guide (Figure $4 a-c)$. The cover screw was placed and the flap was sutured with 4-0 chromic gut (Henry Shein, Melville, NY). A clear vacuum formed retainer was delivered with resin filled on $\# 8$ for an esthetic reason. Five weeks after following implant surgery (Figure 5), options of augmenting the soft tissue or using pink porcelain were presented to the patient. The patient chose soft tissue augmentation. The patient agreed with the diagnosis and treatment plan. A soft tissue subepithelial graft obtained from maxillary tuberosity was inserted with a tunneling procedure which increased vertical dimension (Figure $7 \mathrm{a}-\mathrm{c}$ and 8). Deepithelialized connective tissue was prepared for tunneling graft. After soft tissue healing, the increased vertical dimension of soft tissue was gained (Figure 9 and 10). Five weeks after soft tissue grafting, second stage surgery was done by positioning the flap apically to further improve the dimensions of the mid buccal tissue and provisional crown on upper right central incisor implant (\#8) was placed. Soft tissue healing and contouring with provisional crown was done after two months following the soft tissue grafting (Figure 11).

After placement of a provisional crown, the patient was given several options for the final crown according to the ideal ways. The suggested options were 1) Single all ceramic crown, 2) Single PFM crown and 3) Two (two centrals), Four (lateral to lateral) or Six (canine to canine) anterior crowns according 4) one implant supported crown 


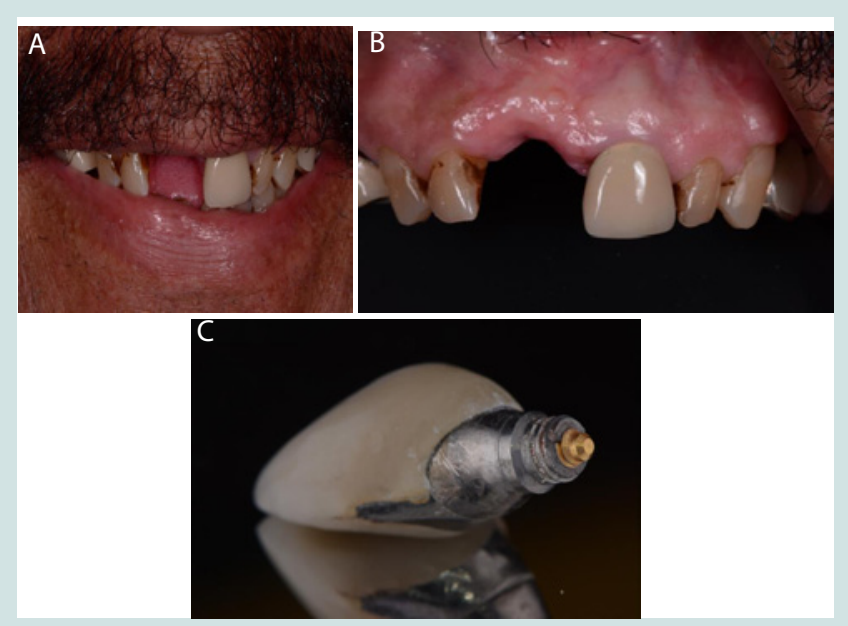

Figure 1: A: Extra-oral Smile View. B: Intra Oral View. C: Fractured Implant Screw with PFM crown.

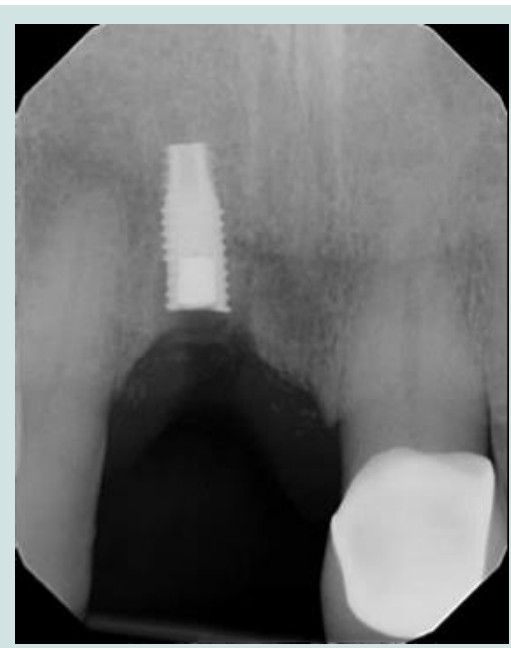

Figure 2: Periapical Radiograph on \#8.

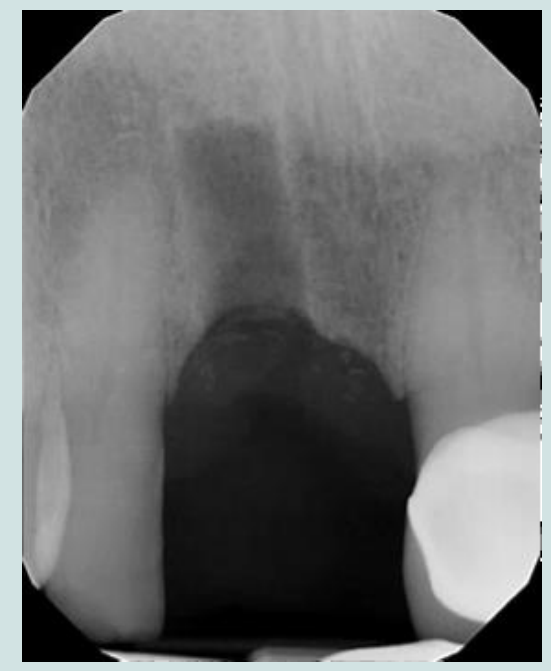

Figure 3: After removing Fractured Implant with trephine.

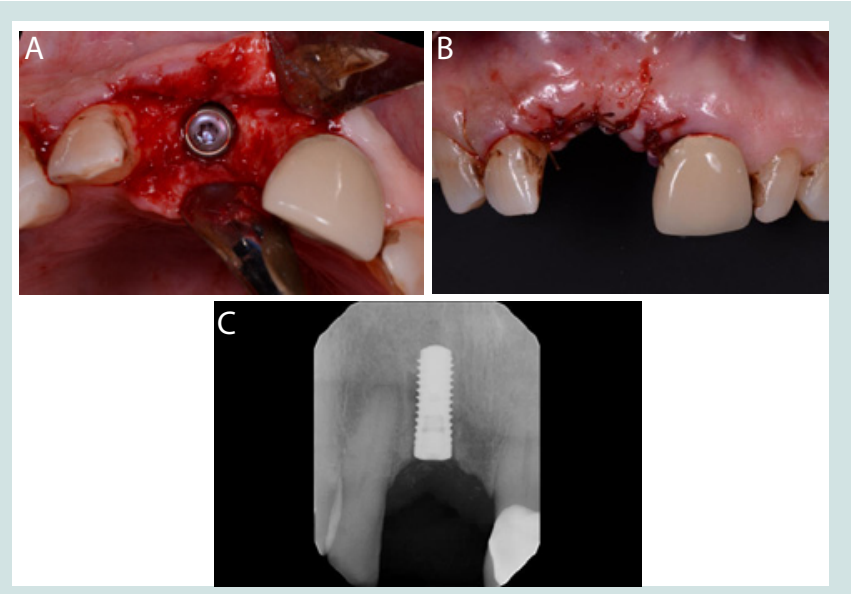

Figure 4: A: Occlusal view of new implant placement. B: After suture. C: Periapical radiograph after implant placement.

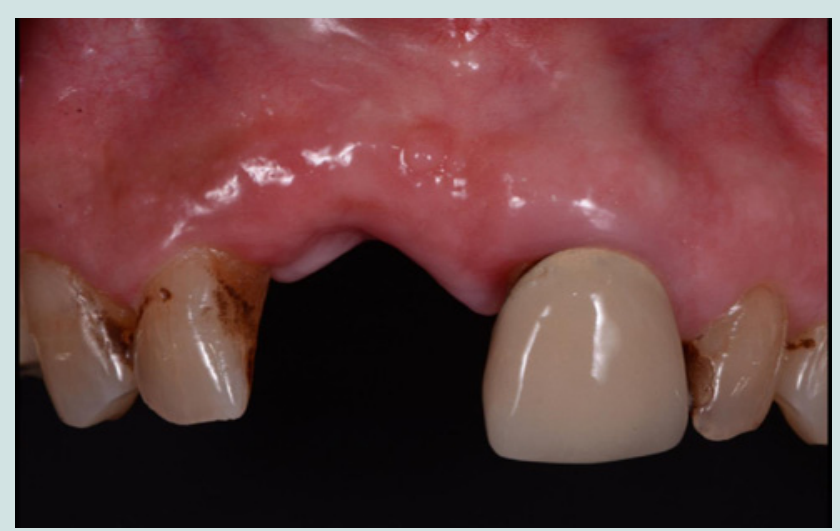

Figure 5: Five weeks after implant placement.

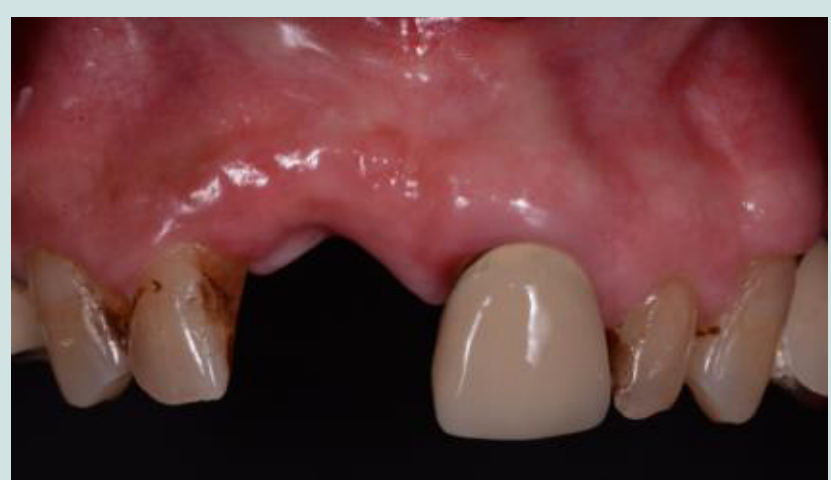

Figure 6: Esthetic problem analysis for the necessity of soft tissue graft.

(\#8) and five laminate veneers (\#6,\#7,\#9,\#10,\#11) to smile designs. However, after listening to all treatment options, patient chose \#8 single restoration and suggested metal crown with labial composite window. The patient already has his suggested implant crown on his upper left first premolar (site \#12) (Figure 12). This kind of treatment in dentistry has been used in pediatric dentistry for esthetic sp crown or in esthetic pontic of fixed bridge on posterior teeth. Finally, the metal crown with labial composite window was installed on \#8 site 

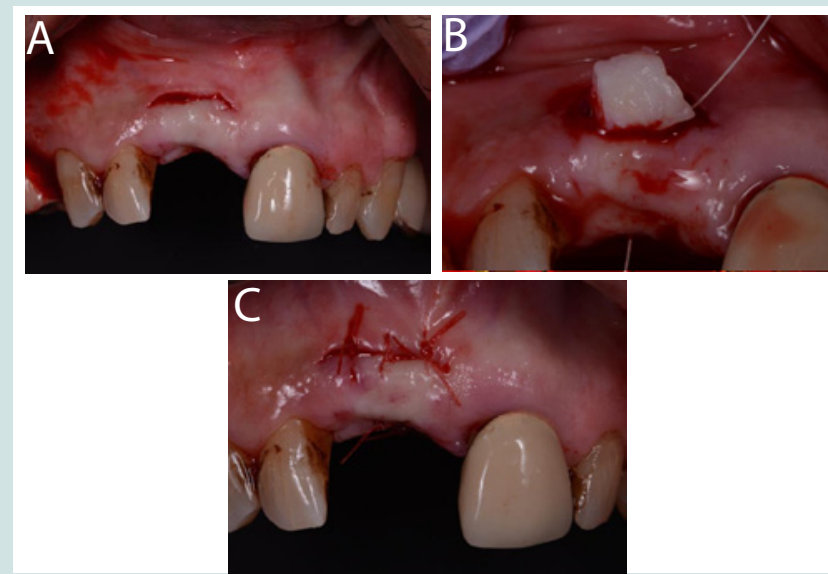

Figure 7: A: Incision for tunneling technique. B: Grafting deepithlized connective tissue. C: Suture after tunneling technique.

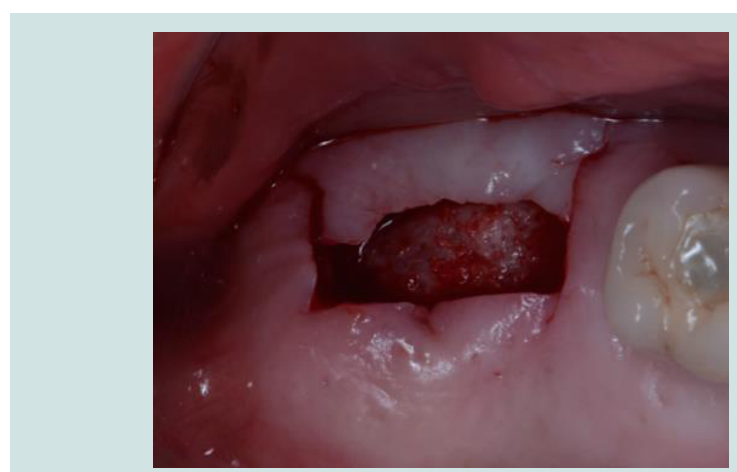

Figure 8: The maxillary tuberosity is the donor site of soft tissue graft.

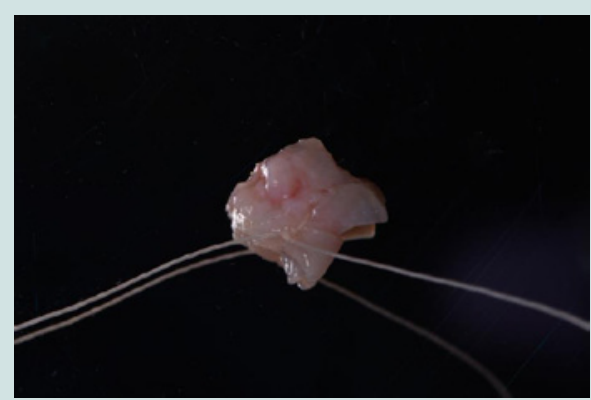

Figure 9: Deepithalized connective tissue for graft.

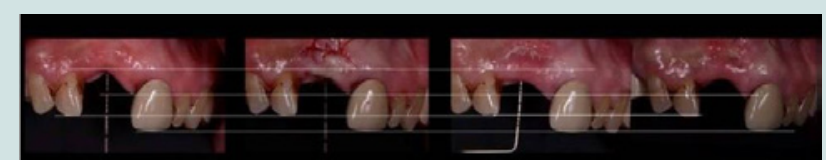

Figure 10: After soft tissue healing, vertical dimension of soft tissue is increased.

(Figure 13).

\section{Discussion}

The notion of aesthetics in dental treatment may be similar or

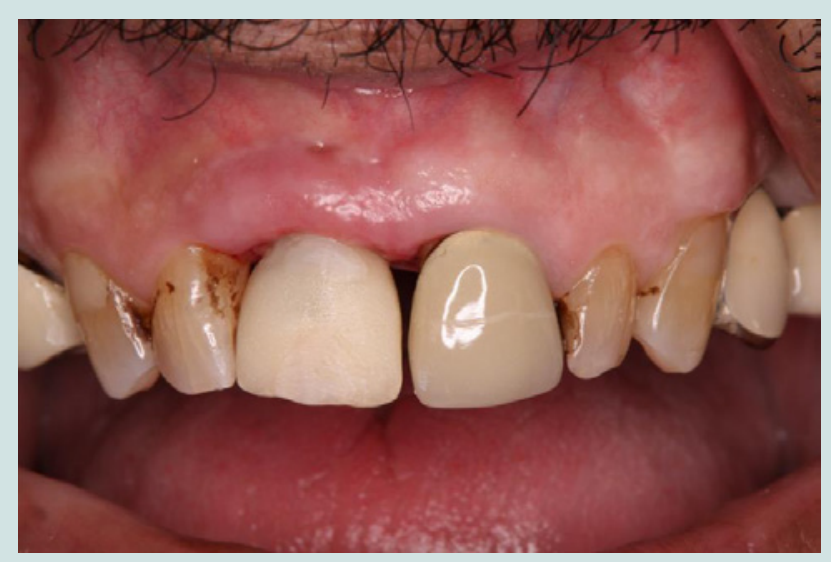

Figure 11: Provisional crown on upper rightcentral incisor( \#8), Two months after soft tissue graft.

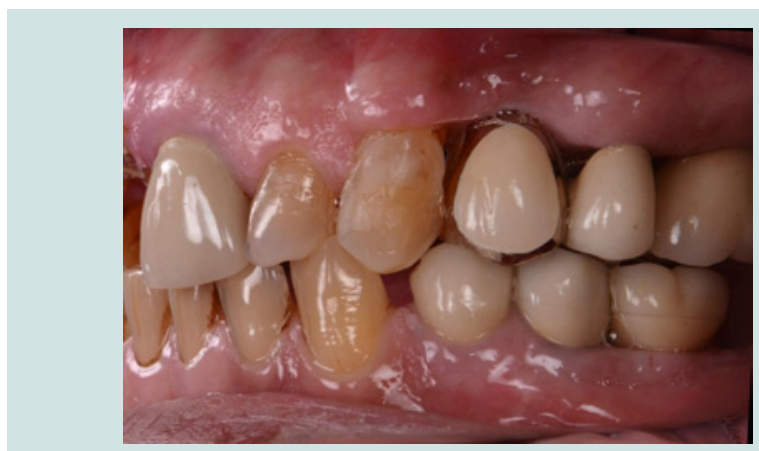

Figure 12: Patient already has the metal implant crown with labial composite window on upper left 1st premolar (\#12).

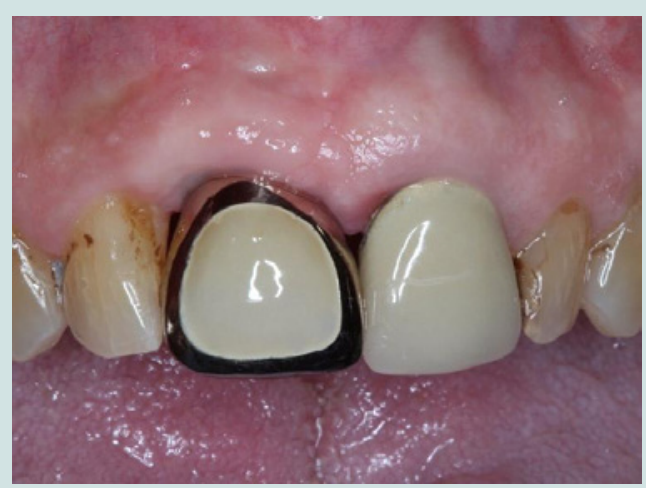

Figure 13: Gold metal implant crown with labial composite window on upper right central incisor (\#8).

very different from clinician and patient point of view [6]. According to the study of Burgueño-Barris, even esthetics is very different within the group of dentists [7]. In general, the average person is less sensitive to aesthetic differences in dental treatment than dentists [8]. Despite this aesthetic difference between the dentists and the patients, most patients choose teeth that mimic the shade and shape of the surrounding teeth when deciding the type of the anterior prosthesis [9]. However, some patients make different decisions than ordinary patients for other reasons, such as their religious, cultural, educational background, and economic background [10]. 
In this patient, the mesio-distal width of $\# 9$ is $10.2 \mathrm{~mm}$, and $\# 8$ is $11.2 \mathrm{~mm}$. The height difference between the apical gingival line of \#9 and $\# 8$ is $2 \mathrm{~mm}$, \#8 is higher than $\# 9$ and there is a periodontal defect at \#8. When informed the patient of these differences, the patient readily understood these differences. When options of single implant crown, fixed crown bridges, and removable dentures are given as a treatment of $\# 8$, the patient selected single implant crown. The patient also agreed with the soft tissue augmentation treatment for \#8. Patient was given a choice to pick palate or maxillary tuberosity as a donor site for his soft tissue graft, patient chose to go with maxillary tuberosity as it is less pain full procedure compared to the graft from palate.

Patient selected the resin facing metal crown compared to type of crowns presented by the dentist to him. The patient already has a resin facing metal implant crown as a treatment method for \#12 in a general local dental clinic. The background for the making the choice of having resin facing metal implant crown on \#12 is, the ceramic chipped on the PFM crown which he had earlier on the same tooth. When a new treatment is required after \#8 implant fractured, the treatment options were selected by the clinician for implant treatment. However, the final selection of the type of crown was chosen by the patient as resin-facing metal crown. When he smiled or talked after treatment, the metal was exposure, but the patient did not concern about this exposure of metal on \#8. Even he considered this exposure metal as strong image of himself.

Recently, there is no report on using resin facing crown or implant crown in adult. According to the study of [11], the study described that the composite resins and thermoplastics are bonded to the metal. This type of pre veneered crown was developed to serve as a convenient, durable, reliable, and esthetic solution to the difficult challenge of restoring severely carious primary incisors. Moreover, reported that the resistance to fracture and attrition is good in pre veneered stainless steel crowns [12]. The main disadvantage is the resin shades which give an artificial look. The study by reported that stainless steel crowns are a highly retentive restoration [13]. However, there was a high prevalence of facing failure with about $1 / 3$ of the facings showing complete or substantial facing loss. Facing failures occurred most commonly at the resin-resin and resin-metal interface

According to Jamil's report, there is a case in which the Amazon tribe required similar treatment methods for religious reasons [14] According to preference studies on the types of anterior prosthesis in general patients, all ceramic, PFM, are preferred to treatments similar to surrounding teeth. This is also the way suggested by dentists. It should be understood that most aesthetic criteria may not apply in all cases when applying the selection criteria of anterior maxillary prostheses with aesthetic needs in dental treatment.

\section{Conclusion}

In this case, we can understand that the patient may not choose the treatment from the opinions presented by the experts but from his esthetic criteria by means of the popularization of information about the aesthetic part of dental care and the factors related to age, race, sex, and economic situation. Also, many dental professionals should keep in mind that the patients can make subjective choices of aesthetics in their own treatment.

\section{References}

1. Dos Santos DM, Moreno A, Vechiato-Filho AJ, BonattoLda R, Pesqueira AA, et al. (2015) The importance of the lifelike esthetic appearance of all-ceramic restorations on anterior teeth. Case Reports Dent pp: 5.

2. Brisman AS (1980) Esthetics: a comparison of dentists' and patients' concepts. J Am Dent Assoc 100: 345-352.

3. Samorodnitzky-Naveh GR, Geiger SB, Levin L (2007) Patients' satisfaction with dental esthetics. J Am Dent Assoc 138: 805-808.

4. Maghaireh GA, Alzraikat H, Taha NA (2016) Satisfaction with dental appearance and attitude toward improving dental esthetics among patients attending a dental teaching center. J Contemp Dent Pract 17: 16-21.

5. Al-Zarea BK (2013) Satisfaction with appearance and the desired treatment to improve aesthetics. Int J Dent 2013.

6. Pithon MM, Santos AM, Campos MS, Couto FS, dos Santos AF, et al. (2014) Perception of laypersons and dental professionals and students as regards the aesthetic impact of gingival plastic surgery. Eur J Orthod 36: 173-178.

7. Burgueño-Barris G, Cortés-Acha B, Figueiredo R, Valmaseda-Castellón $E$ (2016) Aesthetic perception of single implants placed in the anterior zone. A cross-sectional study. Perception of laypersons and dental professionals and students as regards the aesthetic impact of gingival plastic surgery. Med Oral Patol Oral Cir Bucal 21: e488-e493.

8. Kokich VO Jr, Kiyak HA, Shapiro PA (1999) Comparing the perception of dentists and lay people to altered dental esthetics. J Esthet Dent 11: 311-324.

9. Kahng L (2008) Recreating the texture, shape, and color of a natural tooth. Inside Dent 4: 1-3.

10. Grzić R, Spalj S, Lajnert V, Glavicić S, Uhac I, et al. (2012) Factors influencing a patient's decision to choose the type of treatment to improve dental esthetics. Vojnosanit Pregl 69: 978-985.

11. Baker LH, Moon P, Murray JJ (1996) Retention of esthetic veneers on primary stainless steel crowns. J Dent Child 63: 185-189.

12. Walia T, Salami AA, Bashiri R, Hamoodi OM, Rashid F (2014) A randomised controlled trial of three aesthetic full-coronal restorations in primary maxillary teeth. Eur J Paediatr Dent 15: 113-118.

13. Roberts C, Lee JY, Wright JT (2001) Clinical evaluation andparental satisfaction with resin-faced stainless steel crowns. Pediatr Dent 23: 28-31.

14. Jamil $F$ (2014) The use of anterior gold basket crowns among remote Amazonian communities. BDJ 216: 475-476. 